\title{
ANÁLISE dO APLICATIVO KOHA NO COLÉGIO PEDRO II: UM RELATO DE EXPERIÊNCIA
}

\author{
ANALYSIS OF APPLICATION IN COLLEGE KOHA PEDRO II: \\ A EXPERIENCE REPORT
}

Márcia Feijão de Figueiredo ${ }^{l}$

\begin{abstract}
RESUMO
Este artigo relata os testes realizados no Aplicativo Koha do Colégio Pedro II durante o primeiro semestre de 2014. Descreve o Colégio Pedro II e o Sistema de Bibliotecas, Mediatecas e Salas de Leitura para informar quais são as necessidades institucionais no gerenciamento eletrônico de bibliotecas multicampi e centralizado. Apresenta o aplicativo Koha, suas características e o uso no mundo e a adoção no Brasil. Analisa os módulos do aplicativo e o grau de dificuldade encontrado durante os testes. Conclui afirmando que os testes foram realizados com êxito e algumas ressalvas são relatadas, para agenda futura.
\end{abstract}

PALAVRAS-CHAVE: Gerenciamento eletrônico de bibliotecas; Koha; Colégio Pedro II.

\section{ABSTRACT}

This article reports the tests in Koha Software at College Pedro II during the first half of 2014. Describes the College Pedro II and the Library System, with libraries, media librarys and reading rooms to advise what institutional needs in the information library system rand multicampi centralized. Preface the Koha Software, your technical features and use in the world and the adoption in Brazil. Analyzes the software modules and the degree of difficulty encountered during testing. Concludes that the tests were performed successfully and some caveats are related to future calendar.

KEYWORDS: Information Library Sistem; Koha; Colégio Pedro II.

\section{INTRODUÇÃO}

O Colégio Pedro II é uma instituição federal da educação básica de ensino que possui em suas dependências um Sistema de Bibliotecas e Salas de Leitura que contempla do primeiro grupamento da educação infantil até o corpo docente e discente dos programas de pós-graduação, perpassando por programas como o PROEJA, Pronatec e as bibliotecas pertencentes ao Centro de Documentação e Memória, de cunho histórico. Em cada campi existe um espaço designado para atividades com uso de materiais de complementação pedagógica, como livros, periódicos e outros objetos educacionais até dissertações, teses de cátedra, documentos de memória e demais materiais impressos. Para cada segmento existe um tipo de unidade de informação e, no caso dos espaços históricos, as coleções tem valor inestimável e em grande maioria são exemplares únicos. Outras unidades de informação também fazem uso desses recursos como meio de fomento pedagógico a outros idiomas, como as mediatecas de inglês, francês e espanhol, em fase de expansão.

\footnotetext{
${ }^{1}$ Chefe da Seção de Bibliotecas e Salas de Leitura do Colégio Pedro II. E-mail: marciaffigueiredo@gmail.com Recebido em: 10/12/2014 - Aceito em: 19/08/2015
} 
A complexidade e amplitude das unidades de informação no Colégio Pedro II traz a necessidade de utilizar recursos automatizados, trazendo benefícios para os profissionais como o aumento de serviços oferecidos para os usuários e a realização de atividades internas em menor tempo, após a total implantação. Contudo, não existe de modo coordenado e padronizado um trabalho automatizado das rotinas de aquisição, processamento técnico e circulação desses materiais, e cada responsável realiza essas atividades de modo singular e manual, o que demanda maior tempo e produtos e serviços descentralizados.

Diante dessa situação o Colégio Pedro II, através da parceria entre a Diretoria de Tecnologia da Informação e a Seção de Bibliotecas e Salas de Leitura, tem desenvolvido um trabalho visando a automação unificada e padronizada das unidades. Desde 2000 os bibliotecários e a equipe da Tecnologia da Informação da instituição tentam resolver o problema de automação das bibliotecas e a primeira tentativa foi a criação de um aplicativo pela empresa que prestava serviços ao colégio. A partir de 2009 até o término de 2013 a equipe de bibliotecários e o analista de sistemas testaram um sistema gratuito desenvolvido no âmbito nacional, o BibLivre, contudo não houve sucesso ao longo dos testes para as necessidades institucionais porque o aplicativo BibLivre não era multicampi, e para essa funcionalidade não permitia as alterações necessárias, ou seja, que respeita as necessidades e singularidades de cada espaço.

Após o esgotamento de possibilidades de automatizar o Sistema com aplicativos brasileiros, a equipe de Tecnologia da Informação (PRODI/DTI) apresentou para a Seção de Bibliotecas e Salas de Leitura um aplicativo livre e de código aberto internacional, criado em 1999 na Nova Zelândia e de uso consolidado na Europa e nos Estados Unidos, o Koha (OFFICIAL, 2014). A análise de aplicativos livres na Administração Pública obedece ao Art. 11 da Instrução Normativa $n^{\circ}$ 04, de 12 de novembro de 2014, onde o Governo só permite aos órgãos integrantes adquirir um aplicativo desenvolvido por empresas privadas quando as possibilidades livres se esgotam, como informa o Art. 11 inciso II:

II - identificação das diferentes soluções que atendam aos requisitos, considerando:

a) a disponibilidade de solução similar em outro órgão ou entidade da Administração Pública;

b) as soluções existentes no Portal do Software Público Brasileiro (http://www.softwarepublico.gov.br);

c) a capacidade e alternativas do mercado, inclusive a existência de software livre ou software público (BRASIL, 2010);

Diante desse cenário, este trabalho tem por objetivo relatar a análise do aplicativo Koha no Colégio Pedro II, realizado no primeiro semestre de 2014. Na primeira etapa observou-se a necessidade de apresentar o Colégio Pedro II para em seguida descrever como funciona o Sistema de Bibliotecas, quais são os tipos de unidade informacionais e o públicoalvo de cada. Assim, pode-se vislumbrar as necessidades do Sistema para uma escolha adequada. 
A seção seguinte se inicia com um breve conceito do que são aplicativos de código aberto (open source) e descreve como funciona um gerenciador de bibliotecas e o Koha com suas principais características. Na última etapa dessa seção algumas iniciativas brasileiras de uso do Koha são apresentadas, inclusive Institutos Federais de Ensino Superior, categoria na qual o Colégio Pedro II foi equiparado através da Lei 12.677, de 25 de junho de 2012 (BRASIL. 2012).

Após a apresentação do cenário e a descrição do Koha segue um breve relato dos testes, avaliando as maiores dificuldades e facilidades, e no caso de optar pelo aplicativo quais ações devem ser realizadas para a próxima etapa, a implantação no Sistema de Bibliotecas do Colégio Pedro II.

\section{O COLÉGIO PEDRO II E O SISTEMA DE BIBLIOTECAS}

\subsection{O Colégio Pedro II: um breve histórico}

O Colégio Pedro II é uma instituição de excelência na educação básica criado através de um Decreto de fundação em 02 de dezembro de 1837, com o intuito de atender ao Imperador Pedro II, na época com 12 anos. Segundo Dória (1997, p. xi) o Ministro Bernardo Pereira de Vasconcellos tinha "por objetivo criar no Brasil um estabelecimento nacional de ensino que recordasse a grandeza do Colégio de França, considerado o maior monumento cultural da Europa" e levou o Decreto para a assinatura pelo então Regente Pedro de Araújo Lima.

Após sua criação, o Colégio Pedro II tornou-se referência de ensino básico no Brasil. Os professores da instituição passam a participar da criação de outros colégios, como o Instituto de Educação e o Colégio Militar, e diversas personalidades ilustres foram dos corpos discente e docente, dentre eles três Presidentes da República: Rodrigues Alves, Hermes da Fonseca e Washington Luís (COLÉGIO, 2007).

Nos últimos anos, houve a expansão e criação de diversas unidades escolares, e o Colégio se estendeu a outros municípios do Estado do Rio de Janeiro, em Duque de Caxias e Niterói. Em 2012 o Colégio Pedro II foi equiparado aos Institutos Federais de Educação, Ciência e Tecnologia - IFES, o que alterou a estrutura organizacional e ao mesmo tempo passou a oferecer, através da Pró-Reitoria de Pós-Graduação, um Programa de Residência Docente e Mestrados Profissionais, como o de Práticas em Educação Básica e em breve o ProfMat (COLÉGIO, 2014a).

\subsection{Sistema de bibliotecas:}

O Sistema de Bibliotecas e Documentação do Colégio Pedro II foi criado através das Portarias 1.236 e 1.237 de 23 de novembro de 2004 e alterada através da Portaria de 2.810, de 01 de Abril de 2014. Diferente das outras IFES, o Colégio Pedro II possui unidades informacionais estabelecidos ou em fase de criação em todos os segmentos da educação 
básica, uma Biblioteca para atender aos programas de pós-graduação e um Centro de Documentação e Memória, o que torna o Sistema heterogêneo e gestor de tipos diferentes de materiais, além de atender a públicos diversificados.

No âmbito da educação básica há a Educação Infantil e os campi de primeiro segmento, do primeiro ao quinto ano do ensino fundamental, cujas salas de leitura fazem a mediação para o fomento as primeiras letras e o incentivo a leitura. Nos campi de ensino fundamental e médio, as bibliotecas escolares atendem a maioria da comunidade escolar: alunos, professores e técnicos administrativos, com o que podemos chamar de complementação pedagógica, ou seja, insumos para a pesquisa escolar, visando a entrega de trabalhos de disciplina e a leitura recreativa, dispondo de histórias em quadrinhos, periódicos infanto-juvenis e literatura ampla e diversificada. Em alguns campi as mediatecas tem desenvolvido atividades culturais, com o intuito de apresentar aos alunos da educação básica países que falam outros idiomas e suas peculiaridades, incentivando o fomento a outros idiomas, através de recursos multimeios e impressos para o desenvolvimento de atividades.

Na pós-graduação, a Biblioteca da PROPGPEC atende ao corpo discente e docente dos programas de residência docente e aos mestrados. Nesse espaço, o objetivo é prover recursos para as pesquisas desenvolvidas no programa e para as disciplinas oferecidas. Diferente das demais, esse espaço sofre avaliações do MEC e precisa cumprir as determinações para a aprovação dos programas oferecidos.

Finalizando, há as unidades que possuem acervos históricos, cuja intenção é salvaguardar a memória institucional, como é o caso do NUDOM, Antenor Nascentes e da Biblioteca Histórica. Nesses espaços há materiais diversificados e de acesso limitado aos itens, cujo valor pode ser inestimável, e que contribuem não apenas para a memória do Colégio Pedro II mas para a história da educação brasileira. Não há circulação de materiais e os usuários são em grande maioria pesquisadores (COLÉGIO, 2014b).

\subsection{Necessidades do Colégio Pedro II para escolha de um aplicativo}

Para atender as principais necessidades do Colégio Pedro II, é necessário respeitar as tipologias apresentadas no item 2.2, de modo que a sala de leitura atenda as demandas dos alunos do primeiro segmento, assim como a Biblioteca da PROPGPEC tenha as rotinas de catalogação, circulação e gerenciamento satisfatórios.

A Diretoria de Tecnologia da Informação também apresenta algumas necessidades para colaborar com o Sistema de Bibliotecas, Mediatecas e Salas de Leitura. Qualquer aplicativo deve se adequar a infraestrutura adotada pelo Colégio, leia-se servidores, banco de dados, plataformas e licenças estabelecidas através da Pró-Reitoria de Desenvolvimento Institucional. Aplicativos que exigem aquisições apenas para o Sistema de Bibliotecas geram demandas financeiras e equipes exclusivas para o projeto, o que inviabiliza o atendimento imediato a automação de toda a rede. 
Nas recomendações aos Reitores das IFES decorrentes do I Encontro de Representantes de Bibliotecas da Rede Federal de Educação Profissional, Científica e Tecnológica - I ERBI, um dos tópicos era Sistemas informatizados de gerenciamento de bibliotecas. Nesse tópico, "Recomenda-se que cada Instituto adote um único programa (software) de gerenciamento de seus acervos e serviços bibliotecários, com atuação integrada e multicampi" (I ENCONTRO, 2012, p. 5). Na seleção dos programas, recomenda-se adoção de requisitos básicos, como:
a) Formato MARC;
b) Protocolo Z 39.50;
c) Parametrização para os diversos perfis de usuários e perfis de Bibliotecas;
d) Segurança de dados;
e) Parametrização do registro de publicações periódicas em nível de kardex;
f) Suporte online;
g) Sistema multiusuário;
h) Suporte para gerenciamento de conteúdos digitais;
i) Emissão de relatórios dentro dos padrões do MEC e CNPQ;
j) Módulo de aquisição bibliográfica;
k) Módulo de ensino ou unidade organizacional (bibliografia básica e complementar);
1) Suporte a periféricos como leitor biométrico;
m) O programa deve permitir a integração facilitada com diversos sistemas acadêmicos e de segurança;
n) Plano de atualização periódica;
o) Plataforma WEB;
p) Disseminação seletiva da informação;
q) Banco de dados deve ser armazenado em servidor da Instituição;
r) A infraestrutura de comunicação e dados e Internet deve estar disponível em padrões mínimos pela Instituição da Rede (ENCONTRO, 2012 p. 5- $6)$.

Assim, acredita-se que a apresentação de requisitos recomendados pelos bibliotecários das IFES esteja próximo do ideal para um sistema automatizado mas ainda encontra-se distante da realidade atual do Colégio Pedro II. Boa parte dos requisitos estão presentes no aplicativo Koha e a Diretoria de Tecnologia da Informação tem sinalizado condições de atender a recomendação de banco de dados em servidor institucional.

\section{O CONCEITO DE OPEN SOURCE NO GERENCIAMENTO DE BIBLIOTECAS: O SOFTWARE KOHA}

Para compreender como ocorre o gerenciamento de bibliotecas é necessário a apresentação do conceito de código aberto (open source), que permite o compartilhamento amplo e irrestrito. Em seguida, além de apresentar as características do sistema de 
gerenciamento é necessário distinguir as diferenças entre o backoffice e o OPAC que nortearão os leitores na seção que trata das análises dos módulos do Koha.

O Koha é um aplicativo para gerenciamento de bibliotecas de código aberto (open source). Na página inicial da Comunidade Open Source, a "definição do Open Source foi criada pela Open Source Iniciative (OSI) a partir do texto original da Debian Free Software Guidelines (DFSG) e determina que um programa de código aberto deve garantir":

1. Distribuição livre; 2. Código fonte; 3. Trabalhos derivados; 4. Integridade do autor do código-fonte; 5. Não discriminação contra pessoas ou grupos; 6. Não discriminação contra áreas de atuação; 7. Distribuição da licença; 8. Licença não específica a um produto; 9. Licença não restrinja outras pessoas; 10. Licença neutra em relação a tecnologia (PÁGINA, 2014).

O uso do código aberto (open source) é justificável por facilitar a adoção do acesso aberto (open acess) nas instituições, que em contrapartida motiva a adoção de melhorias contínuas no sistema de código aberto, em uma relação cíclica de aprimoramento. Outras justificativas são os custos previsíveis de operação no uso de sistemas de código aberto, o apoio constante da comunidade de adeptos e a visibilidade do código (BELNAVES, 2013, p. 2-3).

\subsection{O gerenciamento de bibliotecas automatizado}

As primeiras abordagens literárias sobre sistemas de gerenciamento de bibliotecas afirmam que "todas as atividades de gerenciamento de bibliotecas estão voltadas para o controle do acervo. Os sistemas suportam a seleção, aquisição, etiquetagem, catalogação e controle de circulação de acervo das bibliotecas" (ROWLEY, 2002, p. 230). As razões para o uso são diversas: redução de tarefas repetitivas, insumos para um processo decisório eficaz, serve como fonte de informação sobre o estado do acervo, possibilidade de compartilhar dados (ROWLEY, 2002, p. 230-231).

Atualmente, os aplicativos de gerenciamento de bibliotecas com mais de 15 anos de desenvolvimento não são apenas robustos e estáveis, mas também cada vez mais capazes de integração com outras ferramentas. Essa capacidade de integração introduz possibilidades de uma nova geração de integração entre sistemas de código aberto e entre estes sistemas e recursos externos baseados na web ${ }^{2}$. (BELNAVES, 2013, p. 2).

\subsection{Revisão de literatura do koha}

O Koha é o primeiro aplicativo mundial livre para gerenciamento de bibliotecas, cujo projeto se iniciou em 1999 e ficou pronto em janeiro de 2000. Na página da Comunidade Oficial é possível conhecer o histórico do aplicativo criado pela Empresa Katipo

\footnotetext{
${ }^{2} \mathrm{O}$ autor apresenta as possibilidades de integração entre o Koha o DSpace e o Vufind (BELNAVES, 2013, p. 4).
} 
Communications, na Nova Zelândia. Desde o início fica caracterizado o viés colaborativo do projeto e após a criação da lista de discussão, em 13 de julho de 2000, há o pedido da Polônia de internacionalizá-lo e no mesmo ano ganha um prêmio da $3 \mathrm{M}$ de inovação em bibliotecas (OFFICIAL, 2014).

$\mathrm{Na}$ Comunidade Oficial do Koha, além do histórico é possível acompanhar o calendário de trabalho, e participar de diversas atividades colaborativas, como a tradução dos códigos e do Koha Wiki, com todas as informações a respeito do aplicativo e as atas de reuniões dos membros. Atualmente, o Aplicativo Koha encontra-se na versão 3.18 (disponível na comunidade oficial desde o dia 10 de dezembro de 2014). Para Fernandez (2013, p. 238)

O Koha é caracterizado por ser não apenas um software de busca para acervos informacionais, mas um pacote completo de gerenciamento de bibliotecas e centros de documentação, com módulos responsáveis pela circulação de materiais, catalogação, aquisições, controle de periódicos, cadastro de usuários, emissão de carteirinhas e etiquetas, além de funcionalidades que favorecem a interação dos funcionários da biblioteca com os usuários.

No Site Libraries.Org é possível saber o número de instituições no mundo que fazem uso do Koha, no qual constam 2.963 bibliotecas que informam o uso nesse diretório ${ }^{3}$, mas acredita-se que o número é muito maior porque alguns Campi do Instituto Federal de São Paulo fazem uso do aplicativo a e a informação é enviada pela biblioteca interessada em fazer parte do Projeto (LIBRARIES.ORG, 2014).

\subsection{O Koha no Brasil}

No Brasil os trabalhos que tratam do Aplicativo Koha são recentes e há poucos casos conhecidos de bibliotecas que testaram e implantaram em efetivo. No Município de São Bernardo do Campo, no Estado de São Paulo houve a implantação multicampi em 2012, abrangendo as bibliotecas públicas e escolares da cidade (PREFEITURA, 2012). Segundo Fernandez (2013, p. 246)

\footnotetext{
Neste momento, o Koha está sendo utilizado para pesquisas e empréstimos nas bibliotecas da cidade, funcionando na intranet da prefeitura. Encontra-se em estudo sua abertura online na internet, o que permitirá a consulta do acervo por toda a população e por outras bibliotecas que queiram realizar intercâmbio de registros bibliográficos via cópia direta ou através do protocolo Z39.50.
}

Em bibliotecas dos Institutos Federais de Educação, Ciência e Tecnologia, IFES ainda não foram apresentados projetos de automação multicampi de bibliotecas utilizando o Koha como solução definitiva até a proposta do Colégio Pedro II em 2014. Mas alguns Campi do IFSP - Instituto Federal de São Paulo tem bibliotecas que fazem uso em separado até que

\footnotetext{
${ }^{3}$ Número verificado no dia 10 de dezembro de 2014 no endereço http://librarytechnology.org/libraries/search.pl
} 
formalize-se uma solução multicampi, como é o caso dos Campi Biriguii ${ }^{4}$, Piracicaba ${ }^{5}$, São Carlos $^{6}$ e Suzano ${ }^{7}$.

\section{ANÁliSE DO KOHA NO COLÉGIO PEDRO II: PRIMEIRAS IMPRESSÕES}

Para explicar os testes realizados no aplicativo, optou-se por descrever a análise exaustiva dos módulos em duas etapas, a primeira foi aprender a utilizar o módulo Administração do Koha, que configura o sistema e determina o modo de uso e a segunda etapa foram os módulos restantes, simulando o uso do aplicativo no cotidiano das bibliotecas, mediatecas e salas de leitura: Usuários, Catalogação (MARC formato bibliográfico), Autoridade (MARC formato autoridade) e Circulação. Os outros módulos também foram testados com êxito, mas com menos exaustão: Ferramentas, Relatórios, Aquisições, Periódicos, Listas. Dada a necessidade de conhecer melhor algumas funções, outros módulos ainda não foram testados com afinco, mas pretende-se fazer novas avaliações posteriormente.

A versão do Koha instalada foi a 3.14.01.000 que, data de novembro de 2013. Os programas utilizados com o Koha foram MySQL versão 14.14 e o Apache 2.2.22 (Debian) e o Zebra 2.0.55.

\section{PRIMEIRA ETAPA:}

\section{Administração do Sistema}

Módulo mais importante e determinante para o desenvolvimento dos trabalhos nos unidades do Colégio Pedro II. Nesse módulo há as Configurações globais do sistema, onde se escolhe o que é possível ou permitido em cada módulo, inclusive a modalidade de autoempréstimo, que não foi adotada pela Seção. A maioria dos problemas observados no início dos testes foram resolvidos através das configurações, como o modo de gerar código de barras, a criação de coleções na parte de exemplares. As regras de circulação são exemplos de questões levantadas pela equipe de bibliotecários resolvidas através do reajuste dos parâmetros globais. Pode-se considerar a administração como uma etapa primeira por exigir mais e frequentemente do administrador atenção nas escolhas feitas no sistema. Apresenta uma caixa de busca onde tudo relativo a um assunto pode ser encontrado ao mesmo tempo. Alguns itens ainda não estavam traduzidos nessa versão.

\footnotetext{
${ }^{4}$ Disponível em: http://bri.ifsp.edu.br/biblioteca/ . Acesso em: 10 dez. 2014.

${ }^{5}$ Disponível em: http://200.162.134.29:8001/cgi-bin/koha/opac-search.pl?q=su: Acesso em: 10 dez. 2014.

6 Disponível em: http://biblioteca.ifspsaocarlos.edu.br:8080/cgi-bin/koha/opac-main.pl Acesso em: $10 \mathrm{dez}$. 2014.

${ }^{7}$ Disponível em: http://szn.ifsp.edu.br:8080/ Acesso em: 10 dez. 2014.
} 


\section{Paramêtros básicos:}

Em Bibliotecas e Grupos, cada espaço de informação passa a ter uma base própria de gerenciamento, e os grupos são criadas por tipologia de espaço, no qual criou-se as bibliotecas escolares, bibliotecas históricas, mediatecas, a Biblioteca de Pós-Graduação e as salas de leitura. Nesse espaço também foi inserido na base os tipos de materiais dos acervos, como os livros, periódicos, multimeios, ebooks, livros didáticos etc.

São esses parâmetros que permitem a realização das etapas posteriores na página do funcionário, como os usuários e a catalogação e na versão OPAC a busca ser filtrada pelo espaço que deseja realizar a pesquisa. Os Valores autorizados foram criados posteriormente para editar a parte de exemplares.

\section{Usuários e circulação:}

Define parâmetros para criar os tipos de usuário e as regras para a circulação dos itens. Aqui se define prazos de empréstimo padrão ou por biblioteca (base). A criação das categorias de usuário (aluno, bibliotecário, auxiliar) não apresentou problemas na parte de circulação, o prazo de empréstimo não foi testado até alguns bibliotecários testarem a circulação e reprovarem as regras padrões. O Tipos de atributos de usuários não foi testado até o presente momento.

\section{Catálogo:}

Neste submódulo não houve testes de todos os parâmetros. A Planilha Bibliográfica MARC (MARC formato bibliográfico) padrão possui todos os campos MARC possíveis e estava em inglês. A primeira parte consistiu em criar uma nova planilha sem excluir o modelo padrão, e nessa nova planilha excluiu-se diversos campos obsoletos ou que a princípio não seriam utilizados, retirou-se as marcações que tornavam alguns campos obrigatórios e traduziu-se para melhor entendimento da equipe. Ainda testou-se a importação de planilhas criadas em demos do Koha e variações com menos campos MARC, pensando no uso simplificado nas Salas de Leitura.

O Tipo de autoridade são planilhas MARC formato Autoridade que criam cabeçalhos. No Koha vieram Nome Pessoal, Entidade Coletiva, Título Uniforme, Nome Geográfico, Nome do Evento.

\section{Parâmetros adicionais}

O Z39.50 é um dos recursos intercambiáveis e facilitador para o trabalho e pode ser configurado pelo administrador do aplicativo, possivelmente o bibliotecário por não exigir conhecimentos avançados em servidores. Os dados necessários para as configurações de cada servidor podem estar em diretórios, como o da Library of Congress $^{8}$, que possui um diretório aberto ou na página de algumas bibliotecas nacionais, como é o caso da Biblioteca da França e da Espanha. Os servidores foram configurados com êxito.

\footnotetext{
${ }^{8}$ Disponível em: http://www.loc.gov/z3950/ Acesso em: 10 dez. 2014.
} 


\section{SEGUNDA ETAPA:}

Entende-se que a segunda etapa dos testes é a prática cotidiana do profissional. Aqui são estudados os itens rotineiros das bibliotecas, como o cadastro e acesso aos usuários, a inserção de registros e exemplares de itens do acervo, bem como as autoridades. Também foram testados a circulação de itens e a emissão de relatórios. Outros módulos foram menos vistos e por isso não inseridos nessa análise preliminar.

\section{Usuários}

Módulo de cadastro e busca de todos os usuários: dos bibliotecários e demais funcionários aos usuários dos produtos e serviços das bibliotecas, mediatecas e salas de leitura. Para o administrador, também é possível dar permissões a cada usuário cadastrado, o que no caso dos funcionários aumenta ou diminui o acesso aos módulos de gerenciamento. Aquele que tem todas as permissões se equipara ao administrador do sistema, descrito no Koha como superlibrarian. Alguns recursos não estão totalmente separados e retirar o acesso restringe muito o funcionário, demandando a necessidade de políticas claras no momento de entrar em produção e cuidado dos chefes de bibliotecas, como o acesso ao registro, que pode ser alterado por quem não o fez. É um opção a ser sugerida a comunidade internacional que desenvolve o aplicativo.

\section{Catalogação e Autoridade}

Como visto no módulo Administração, são os módulos que tratam da catalogação dos acervos e da criação dos catálogos de autoridades e tem duas maneiras de realizar: abrindo a planilha e fazendo a catalogação ou tentando a migração através do protocolo Z39.50. São os módulos mais exigentes do aplicativo, pois a planilha se encontra em formato MARC e cabe ao bibliotecário ter conhecimentos mínimos sobre catalogação em máquina para desenvolver suas atividades.

Esses módulos têm por objetivo criar registros de obras e autoridades que não pertencem a nenhuma base, e sim ao coletivo. No caso da catalogação de acervo, após o registro ser criado abre-se a opção de criar exemplar, que nesse caso é pertencente a alguma biblioteca, mediateca ou sala de leitura e recebe informações do item, como a forma de aquisição, data de entrada no sistema, número de patrimônio, dentre outras.

Os testes de usuários talvez foram os mais difíceis de realizar. Como ainda não havia pleno domínio das regras de circulação, alguns bibliotecários se queixaram dos prazos e do quantitativo, mas as queixas não são erros do Koha e sim da parametrização de prazos utilizados durante os testes. Observa-se a necessidade de estabelecer em uma política institucional, com o propósito de padronizar ou criar critérios para o uso dessas regras. $\mathrm{O}$ uso do módulo se mostrou fácil e simples, e pode ser realizado por qualquer funcionário da equipe capacitado nesse módulo. Também é possível restringir usuários de modo manual, caso desrespeite o prazo de devolução do item ou outra regra do espaço. 


\section{Relatórios}

O que aparentava ser um problema para a equipe posteriormente se revelou como uma grande surpresa. A interface do módulo Relatório é pouco amigável e o Assistente de Relatórios não foi compreensível de imediato para o teste. Contudo, a equipe foi surpreendida com a apresentação da subseção Criar a partir de $S Q L$, onde a comunidade colaborativa do Koha, dentro do próprio programa disponibiliza uma Biblioteca com os códigos que geram relatórios diversificados, provendo independência das equipes no uso e execução.

\section{CONSIDERAÇÕES FINAIS}

Após a realização dos testes em todos os módulos, alguns com maior ou menor profundidade é possível afirmar que o Aplicativo Koha é adequado e atende plenamente as demandas do Colégio Pedro II. Como suas configurações são customizáveis e cada base é independente, pode-se criar ambientes adequados para cada tipo de espaço de informação como, por exemplo, as planilhas de catalogação podem ter poucos campos de preenchimento para as salas de leitura enquanto que tipos de materiais com maior grau de exigência podem utilizar planilhas exaustivas, como os acervos históricos e raros. Do mesmo modo, é possível tipificar acervos, usuários e criar regras de circulação por tipos de unidades e dentro de cada biblioteca, mediateca ou sala de leitura criar regras internas próprias e adequadas ao seu público-alvo e acervo existentes.

Por outro lado, é importante frisar que um aplicativo com tantos desdobramentos e customizações necessita de mão de obra adequada e interessada em implantar como projeto. A diretoria de tecnologia da informação deve ser parceira para prover uma infraestrutura adequada e os bibliotecários gerentes do sistema e as chefias das bibliotecas devem estudar com afinco as possibilidades de gestão do aplicativo para tornar o trabalho mais dinâmico e pleno, centralizando o gerenciamento no Koha.

\section{REFERÊNCIAS}

BELNAVES, Edmund. From OPAC to Archive: integrated discovery and digital libraries with open source. In: IFLA GENERAL CONFERENCE AND ASSEMBLY, 79., 2013, Singapure. Future libraries: infinite possibilities: inspiring solutions emerging from open source. Singapure: IFLA. 2013. Disponible: http://library.ifla.org/79/1/108-balnaves-en.pdf Acess: 10 dec. 2014.

BRASIL. Instrução Normativa ${ }^{\circ}$ 04, de 12 de novembro de 2014. Disponível em: http://www.governoeletronico.gov.br/sisp-conteudo/nucleo-de-contratacoes-de-ti/modelo-decontratacoes-normativos-e-documentos-de-referencia/instrucao-normativa-mp-slti-no04/ Acesso em: 25 ago. 2014.

BRASIL. Lei no 12.677, de 25 de junho de 2012. Disponível em: http://www.planalto.gov.br/ccivil_03/_ato2011-2014/2012/lei/L12677.htm Acesso em: 07 out. 2014. 
COLÉGIO PEDRO II. Colégio Pedro II e a história da educação no Brasil. Rio de Janeiro: Folha Dirigida, 2007.

. O Colégio Pedro II hoje. Rio de Janeiro: Colégio Pedro II, 2014a. Disponível em: http://www.cp2.g12.br/component/content/article/83-cpii/1635-o-col\%C3\%A9gio-pedro-iihoje.html Acesso em: 01 nov. 2014.

COMISSÃO DE ATUALIZAÇÃO DA MEMÓRIA HISTÓRICA DO COLÉGIO PEDRO II. Projeto de atualização da memória histórica do Colégio Pedro II. In.: DÓRIA, Escragnolle. Memória histórica do Colégio de Pedro Segundo: 1837-1937. Brasília: Instituto Nacional de Estudos e Pesquisas Educacionais, 1997.

DÓRIA, Escragnolle. Memória histórica do Colégio de Pedro Segundo: 1837-1937. Brasília: Instituto Nacional de Estudos e Pesquisas Educacionais, 1997.

ENCONTRO DE REPRESENTANTES DE BIBLIOTECAS DAS INSTITUIÇÕES DA REDE FEDERAL DE EDUCAÇÃO PROFISSIONAL, CIENTÍFICA E TECNOLÓGICA, 1, 2013, Brasília. Recomendações. Brasília: CBBI, 2013.

FERNANDEZ, Rafael Saad. O uso de softwares livres na gestão pública de acervos informacionais: o caso do Koha nas bibliotecas de São Bernardo do Campo. Inf. Inf., Londrina, v. 18, n.2, p. 231 - 248, maio/ago., 2013.

http://www.uel.br/revistas/uel/index.php/informacao/article/view/16174

LIBRARIES.ORG: A directory of libraries throughout the world. Disponível em: http://librarytechnology.org/libraries/ Acesso em: 10 dez. 2014.

OFFICIAL website of Koha Library System. About Koha. Disponível em: http://kohacommunity.org/ Acesso em: 01 mar. 2014.

PÁGINA inicial da Comunidade Open Source. In.: SOFTWARE Livre Brasil. Disponível em: http://softwarelivre.org/open-source-codigo-aberto Acesso em: 31 out. 2014.

PREFEITURA Municipal de São Bernardo do Campo. São Bernardo implanta sistema pioneiro de processamento de livros nas bibliotecas da rede. São Bernardo do Campo: Portal do Grande ABC, 2012. Disponível em:

http://www.portaldograndeabc.com/pgabc/noticias/noticia.php?sao-bernardo-implantasistema-pioneiro-de-processamento-de-livros-nas-bibliotecas-da-rede $\& n=7560$. Acesso em: 10 dez. 2014.

ROWLEY, Jennifer. A biblioteca eletrônica. Brasília: Briquet de Lemos, 2002.

UNIVERSIDAD Nacional de La Plata. Koha: sistema integrado de gestión de bibliotecas: manual de la internet para uso de los bibliotecarios. Plata, AR: UNLP, 2009. Disponível em: http://koha.unlp.edu.ar/uploads/docs/manual_intra.pdf Acesso em: 05 ago. 2014. 


\section{AGRADECIMENTOS}

Para a realização dos trabalhos que possibilitaram esse relato de experiência é necessário agradecer publicamente a algumas pessoas. Em primeiro lugar, a equipe de Tecnologia de Informação do Colégio Pedro II, Professor Luiz Francisco Dias Pereira e Fabrício Soares que me apresentaram o Koha e o colocaram no servidor teste, além de colaborarem integralmente durante todo o processo. E aos bibliotecários Amanda Martins Moraes, do IFSP Birigui, por orientar os primeiros usos e se dispor a vir até ao Colégio Pedro II para ministrar uma palestra sobre a implantação na sua biblioteca, ao Thiago Murakami, da USP, que disponibilizou a ideia em seu blog e demos na internet para testes comparativos, e a Lehy Chung Baik da UERJ, que durante o primeiro semestre trabalhou conosco diariamente na Seção de Bibliotecas e Salas de Leitura. Agradeço também a equipe de bibliotecários do Colégio Pedro II que tem colaborado em efetivo para a implantação de uma solução multicampi, e durante o período de testes trouxe relatórios sobre o uso rotineiro do Koha em suas bibliotecas.

Como citar este documento:

FIGUEIREDO, Márcia Feijão de. Análise do aplicativo Koha no Colégio Pedro II: Um relato de experiência. Revista Digital de Biblioteconomia e Ciência da Informação, Campinas, SP, v. 13, n. 3, p. 653-665, set. 2015. ISSN 1678-765X. Disponivel em: <http://periodicos.sbu.unicamp.br/ojs/index. php/rdbci/article/view/2125>. Acesso em: 18 Set. 2015. 